\title{
Journal of Chemical Metrology
}

A scientific open access journal in the field of analytical chemistry and accreditation

Volume: 14 Year: 2020 Issue: 2 July-December

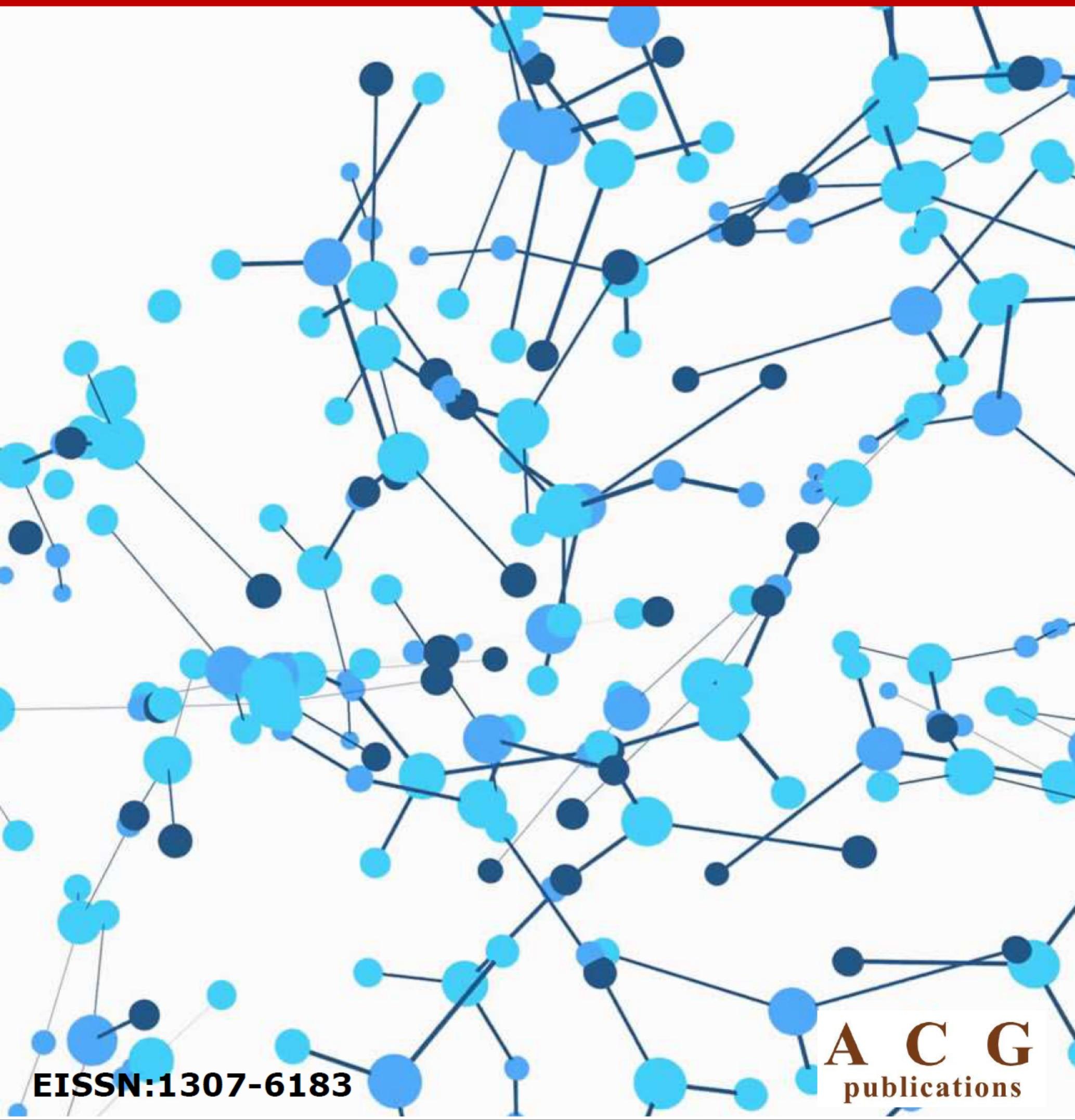




\section{Editor-in chief}

Editor-in-Chief Mustafa Özyürek

Editor-in-Chief Ahmet C Goren

Book Review and Review Article Editor John Warren

\section{Editors}

$\begin{array}{ll}\text { Ewa Bulska } & \text { Florbela Dias } \\ \text { Mahmut Durmuş } & \text { Carlos A. Gonzales } \\ \text { Ahmet C Gören } & \text { ilhami Gülçin } \\ \text { Byungjoo Kim } & \text { Jin Seog Kim } \\ \text { Turgut Kılıç } & \text { Ivo Leito } \\ \text { Bertil Magnusson } & \text { Nuri Nakiboglu } \\ \text { Masahiko Numata } & \text { Mustafa Özyürek } \\ \text { Kenneth W. Pratt } & \text { Marina Ricci } \\ \text { Michela Sega } & \text { Miloslav Suchánek } \\ \text { John Warren } & \text { Steven Westwood }\end{array}$

\section{Language Editors}

John Warren

\section{Abstracting \& Indexing}

Journal of Chemical Metrology is abstracted and Indexed in: Chemical Abstracts Service; ESCI Web of Science by Clarivate Analytics (formerly Thomson Reuters); SCOPUS, Google Schoolar; ProQuest; EBSCOhost, Crossref; $i$-Journals; $i$-Focus.

\section{Publisher}

\section{ACG Yayıncılık Basın Yayın Sanayi ve Ticaret Limited Şirketi}

Yenikent Mahallesi, Fırat Caddesi, 1/3, Gebze, Kocaeli, İstanbul, Türkiye

+90850305 0572 - www.acgpubs.org - info@acgpubs.org

\section{$2020 @$ ACG Publications. All Rights Reserved}

\section{Instruction For Authors}

Manuscripts should be prepared in English using a word processor.

Review Articles are critically evaluated on the specific area in chemical metrology, analytical chemistry and accreditation. If you would like to contribute to the journal with a review article, the authors must initially contact the editorial office by email to info@acgpubs.org, as such articles are normally invited.

Original Articles, CRM Report Articles and Discussion Articles are manuscripts describing new chemical measurements (new CRM report for the CRM Report Articles) and also discussions on the modern analytical techniques, results, new applications to other areas, such as bioanalytical and pharmaceutical studies . In determining the suitability of submitted articles for publication, particular scrutiny will be placed on the degree of novelty and significance of the research and the extent to which it adds to existing knowledge in analytical chemistry. Discussion papers on the fundamentals of analytical chemistry and Metrology in Chemistry and Biology including educational facilities are welcome. These manuscripts should reflect completed investigations rather than fragmentary parts of a larger study. In order to reduce manuscript length, specific experimental 
details, and some spectra and/or figures should be made available as supplementary material from the corresponding author.

Authors are must use templates (Template file for original article) for the preparation of manuscripts. The section order and topics should be determined by the authors for the discussion articles if it has no experimental data. Manuscripts should be compiled in the following order: Title page; Abstract; Graphical abstract (in PAMS only), Keywords; Introduction, Materials and Methods, Results and Discussion, Acknowledgments; Appendixes (as appropriate); References; using a decimal system for subsections. Novelty statements of manuscript must be provided and authors

1. Introduction

2. Experimental

3. Results and Discussion

4. Conclusion

Acknowledgements/Supporting Informations

References.

Short Report Articles are suitable for reporting the urgent results of the large study, or new application of known analytical methods. Small modifications and validation data of known methods should be prepared as a short report. Brief discussion on the chemical metrology are welcome in short report form. In order to reduce manuscript length, specific experimental details, and some spectra and/or figures should be made available as supplementary material from the corresponding author.

Authors are must use templates (Template file for short report ) for the preparation of manuscripts.

1. Sample Source

2. Previous Studies

4. Present Study

Acknowledgements/Supporting Informations

References

Special Issues, Letter to Editor and Book Reviews are collections of articles on the specific topics in areas related to aims and scope of journal published in the journal. Offers for the special topics must be applied to the editorial office.

As the manuscript language is English, any author who is not fluent enough in English is encouraged to consult a fluent colleague or a paid editing service for the preparation of the manuscripts. Manuscripts having language deficiencies, i.e. grammar, fluency, etc., create heavy problems during the review process. Such manuscripts might be returned to the authors for correcting the language deficiencies.

Novelty statements of submitted manuscript must be provided as MS word file item by item. The maximum item should be 6 for the novelty statement.

A graphical abstract must be provided during submission. The dimensions of the graphical abstract must be $6.5 \mathrm{~cm}(\mathrm{~h}) \mathrm{x}$ $12.5 \mathrm{~cm}$ (I). Please do not use the portrait version of graphical abstract. The graphical abstract must briefly show the contents of the abstract. Only structure of compound or picture of species not allowed for the graphical abstract.

Manuscripts submitted to ACG publications are routinely screened by a software to check the originality of the submitted articles. It should be noted that ACG publications are committed to deterring plagiarism and selfplagiarism. A plagiarism report must be uploaded during submission of manuscript.

Title of the manuscript should be as brief as possible and typed to the template file with affiliation and addresses of all the authors, including corresponding author with an asterisk. ORCID of all authors should be added as shown in template of manuscripts. The e-mail address, phone and fax numbers of the corresponding author should be provided as a footnote on the title page. Abstracts of all kinds of submissions should be prepared with a maximum 200 words.

Authors must adhere to SI units. When using a word which is or is asserted to be a proprietary term or trade mark authors must use the symbol $\hat{A} \circledast$ or TM or alternatively a footnote can be inserted using the wording below:

Journal citation

A.C. Goren, B.N. Zhou and D.G.I. Kingston (2003). Cytotoxic and DNA damaging activity of some aporphine alkaloids from Stephania dinklagei, Planta Med . 69, 867-868.

Chapter citation

A. Ulubelen and G. Topcu (1992). Diterpenoids from Salvia species and their pharmacological activities, Studies in Natural Products, ed: Atta-ur Rahman, Elsevier Science, Amsterdam, Netherlands, pp.363-381. 
Book citation

R.P. Adams (1995). Identification of essential oil components by gas chromatography/mass spectroscopy. Allured Publishing Co. Carol Stream, Illinois.

\section{Plagiarism Check and Ethics}

Any manuscript submitted, soon to be submitted or in press at any other journal will not be considered by Journal of Chemical Metrology (JCM), and it is authors responsibility to inform the Editor of Journal of Chemical Metrology if such event exists. If the submitted manuscript is a revised version of a previously rejected by JCM, the authors must indicate previous submission in their cover letter and explain the reason/changes that they made in the revised one.

The Ethical Guidelines for Publication in Journals and Reviews issued by the European Association of Chemical and Molecular Sciences are applied by Journal of Chemical Metrology. Authors of all the manuscripts submitted to JCM automatically accept the guidelines given in the Ethical Guidelines for Publication and Reviews and the authors have to provide the ethical board approved document informations ( the number and date and ethical board name of ethical approval) in the main text of manuscript and related data should be available in supporting information file of manuscript, if necessary or requested by the editorial office. The following studies strongly needs ethical board approval eg. any of in vivo studies on any animal and human body, studies of endangered species in nature, information about the people including any kind of survey data etc. For detail please see the COPE guidelines.

Authors are encouraged to attach an authenticated report during the submission to make sure that there is no plagiarism problem. Manuscripts submitted to JCM publications are routinely screened by a software to check the originality of the submitted articles. It should be noted that JCM publications are committed to deterring plagiarism and self-plagiarism

ACG Publications journals use iThenticate ${ }^{\circledR}$ software to check the originality of submitted manuscripts for plagiarism. If a duplication is detected by the editorial office and reviewers, the manuscript will directly be rejected. If the authors use the same sentences of their or another author's previous work with citation without quotation mark, it will still be considered as self-plagiarism and plagiarism, respectively. Journal of Chemical Metrology has the right of removing any article published in Journal of Chemical Metrology, and banning the authors submitting their studies in future if any ethical violation is identified.

\section{Copyright}

It is a condition of publication that authors vest or license copyright in their articles, including abstracts, in ACG Publications. This enables us to ensure full copyright protection and to disseminate the article, and the Journal, to the widest possible readership in electronic formats as appropriate. Authors must accept the articles published in the journal for free all around the world. To read and download published papers is free for scientific purposes.

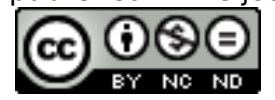

\section{Supplementary Material}

Supplementary materials could be sent together with manuscript submission such as spectra, video, Picture etc.

\section{Publication Fee}

Journal of Chemical Metrology is an OPEN ACCESS journal. ACG Publications is happy to announce continuation of the publication of Journal of ChemicalMetrology completely free of charge for two years and as JCM papers are now supported by Troyasil HPLC Column Technologies. On this occasion, we would like to thank Troyasil HPLC Column Technologies ( www.troyasil.com) for their great support to our scientific community. As a result of this support, there is no Article Processing Charge (APC) in Journal of Chemical Metrology. Submissions and publishing are free of charge for all authors for the next two years.

The authors are charged a fee for English language corrections and/or journal format corrections requested by the authors or editorial team. These services are not considered within the free publication criteria of related journals of ACG PUBLICATIONS.

\section{Withdrawal of a Manuscript}

If the authors intend to withdraw their manuscript after it has been peer reviewed, or after it has been typeset, but not yet published, you will be asked to pay according to the following:

For peer review:200 USD per article

For peer review and typesetting: 300 USD per article

\section{Proof Corrections}

The proof corrections must be done carefully by the authors. When proof corrections are returned to Journal further corrections are not allowed. 
Erratum or Publisher Correction. Notification of an important error made by the journal that affects the publication record or the scientific integrity of the paper, or the reputation of the authors or of the journal.

Corrigendum or Author Correction. Notification of an important error made by the author(s) that affects the publication record or the scientific integrity of the paper, or the reputation of the authors or the journal.

Retraction. Notification of invalid results that affect the reliability of a previously published article. The original article is marked as retracted but remains available to readers, and the retraction statement notifying readers of the invalidity of the published paper is bi-directionally linked to the original published paper.

Addendum. Notification of additional information about a paper. Addenda are published when the editors decide that the addendum is crucial to the reader's understanding of a significant part of the published contribution. Addenda include Editorial Expression of Concern, which is an editorial statement alerting our readership to serious concerns with the published paper. Editorial Expressions of Concern are typically updated with another amendment once further information is available. The editors may request additional information after publication of the article from the authors and it can be available on the page of the article.

\section{Peer Review Policy}

All published research articles in Journal of Chemical Metrology have undergone rigorous single blind peer review, based on initial editor screening and anonymized refereeing by expert referees. 


\section{Contents}

Discussion Article

Ivo Leito and Irja Helm

Metrology in chemistry: some questions and answers - $\mathbf{p . 8 3 - 8 7}$

Original Article

Adel Shehata, Abdulrahman Alaskar, Mohammed Alrashed, Abdullah Alosaimi, Fahad Alkharraa and Abdulrahman Alzahrani Certification of sodium benzoate solution reference material by HPLC-UV, LC-MS/MS and UV-VIS-NIR spectrophotometry for food and drug analysis - p.88-105

Original Article

Kalpana Patel, Priyanka Shah, Purvi Shah and Tejal Gandhi

UV-spectrophotometry-assisted chemometric methods for simultaneous determination of ambroxol hydrochloride and doxofylline in pharmaceutical formulation - p.106-113

Original Article

Aslı Baysal, Hasan Saygin and Gul Sirin Ustabasi

Impact of test conditions on the bacterial bioassay in the presence of TiO2 nanoparticles - p.114-124

Original Article

Dimal Shah, Ishita Gondalia, Vandana Patel, Ashok Mahajan and Usmangani K. Chhalotiya

Stability indicating liquid chromatographic method for the estimation of remogliflozin etabonate - p.125-132

Original Article

Zeynep Kalaycıoğlu, Merve Kopar and F. Bedia Erim

Oleuropein levels of Anatolian olive leaves and correlated antioxidant, antidiabetic, and anti-inflammatory activities -

p.133-141

\section{Original Article}

Devansh Kansara, Usmangani K. Chhalotiya, Hetaben M. Kachhiya and Ishita Patel

Development of TLC method for simultaneous estimation of novel combination of amlodipine besylate, rosuvastatin

calcium, and fimasartan potassium in synthetic mixture - $\mathbf{p . 1 4 2 - 1 5 2}$

Original Article

Muge Guleli, Sezin İssever, Cem Caliskan and Mahmut Ozbek

Determination of simethicone in different drug formulations by gravimetry and comparison with the FTIR method -

p.153-159

Original Article

Merve Bat Özmatara and Şule Dinç Zor

Achievement of antioxidants from Abelmoschus esculentus L. seeds using ultrasound-assisted extraction optimized by the help of experimental design approach - p.160-168

Original Article

Arzu Morkoyunlu Yüce and Hüseyin Altundağ

Assessment of the relationship between some physico-chemical properties of soil and soil algae in micro basin scale in Kocaeli - p.169-176 
Original Article

Sibel Mentese and Batuhan Bas

A year - round monitoring of ambient volatile organic compounds across Dardanelles strait $\mathbf{- p . 1 7 7 - 1 8 9}$ 